\title{
EDUCATION 4.0 TO SUPPORT ENTREPRENEURSHIP, SOCIAL DEVELOPMENT AND EDUCATION IN EMERGING ECONOMIES
}

\author{
Santiago-Omar Caballero-Morales \\ Universidad Popular Autonoma del Estado de Puebla (UPAEP), Puebla, Mexico \\ Email: santiagoomar.caballero@,upaep.mx \\ José-de-Jesús Cordero-Guridi \\ Universidad Popular Autonoma del Estado de Puebla (UPAEP), Puebla, Mexico \\ Email: josejesus.cordero@upaep.mx \\ Ricardo-Iván Álvarez-Tamayo \\ Universidad Popular Autonoma del Estado de Puebla (UPAEP), Puebla, Mexico \\ Email: ricardoivan.alvarez01@upaep.mx \\ Luis Cuautle-Gutiérrez \\ Universidad Popular Autonoma del Estado de Puebla (UPAEP), Puebla, Mexico \\ Email: luis.cuautle@upaep.mx
}

Received: 15 October 2020. Revision received: 18 December 2020. Accepted: 28 December 2020

\begin{abstract}
As a complement to Industry 4.0, the term Education 4.0 has been defined as the evolution of traditional education considering the new digital age's technological tools, combining real and virtual world information. For emerging economies, the implementation of Education 4.0 is an essential asset for future economic and social development. In this context, the present work describes a set of conceptual Education 4.0 models to support three essential aspects in Latin American economies: entrepreneurship of small and medium enterprises, social welfare, and engineering education. These models highlight the human efforts and technological features required to adopt Education/Industry 4.0 in these aspects successfully.
\end{abstract}

KEYWORDS: Education 4.0, Entrepreneurship, Social Support, Manufacturing 4.0.

JEL CLASSIFICATION: I23, L31, O14, O32

Reference: Caballero-Morales, S.O., Cordero-Guridi, J.J., Alvarez-Tamayo, R.I., \& Cuautle-Gutiérrez, L. (2020). Education 4.0 to Support Entrepreneurship, Social Development and Education in Emerging Economies. International Journal of Entrepreneurial Knowledge, 8(2), 89-100. doi: 10.37335/ijek.v8i2.119

\section{INTRODUCTION}

The recent technological advances on smart systems, interconnectivity, automation, and artificial intelligence, have contributed to defining the "fourth industrial revolution" or Industry 4.0 (I4.0). Specifically, I4.0 considers the following technologies integrated into Cyber Physical Systems (CPS): Big Data, Autonomous Robots, Simulation, Universal System Integration, Industrial Internet-of-Things (Io'T), Cybersecurity, Cloud Computing, Additive Manufacturing and Augmented Reality (Antonelli et al, 2019; Motyl et al, 2017).

As a consequence, I4.0 is expected to lead to new business opportunities and models, automatization of business-processes, development of new products and services, higher quality, real-time enabled CPS, development of smart factories and knowledge economy (Bogoviz, 2019; Motyl et al., 2017). Particularly, 


\section{INTERNATIONAL JOURNAL OF ENTREPRENEURIAL KNOWLEDGE}

Issue 2, volume 8, ISSN 2336-2960 (Online)

www.ijek.org

knowledge economy is associated with entrepreneurship growth and innovative development of socioeconomic systems (Bogoviz, 2019). Within the social context, the core of I4.0 prioritizes the future challenges relative to prosperity and quality of life, consolidation of resources, and promotion of innovation transfer and networking (Mogos et al., 2018).

However, to achieve a successful I4.0 implementation, the future professional faces important challenges due to its specific skills, qualifications and competencies (Benesova \& Tupa, 2017). In recent works, these competencies are categorized into four main groups: Technical, Methodological, Social and Personal (Hecklau et al., 2016; Benesova \& Tupa, 2017).

This is the reason to evolve the standard education system to the Education 4.0 (E4.0) paradigm. This system is expected to combine real and virtual world information through virtual learning environments (VLEs) and augmented reality. Due to the economic nature of the required technological tools, it is recommended to establish partnerships between businesses/factories and higher education institutions (Benesova \& Tupa, 2017).

Although this is a challenge in emerging economies, it also represents an opportunity to develop portable I4.0 and E4.0 in small and medium enterprises, and engineering education modules considering limited resources. The present work addresses this scenario, and a set of conceptual E4.0 models are developed to support entrepreneurship and engineering education in Mexico. These models can be used as a guideline for development of needed training and consultancy courses for I4.0 implementation.

This work is structured as follows: in Section 2 a review on specific requirements for E4.0 is presented, then, in Section 3 these are adapted into the first conceptual model to address entrepreneurship for small and medium enterprises. Section 4 and 5 present the adapted features for the second and third conceptual models to address social welfare and engineering education. Finally, Section 6 presents our conclusions and future work.

\section{EDUCATION 4.0 FEATURES AND PERSON-FOCUSED APPROACH}

Figure 1 presents an overview of the nine trends identified in Mogos et al. (2018) and Das et al. (2020) for E4.0. The present work extends on this by identifying the I4.0 features which are associated with each E4.0 trend.

Figure 1 E4.0 trends associated with I4.0 features

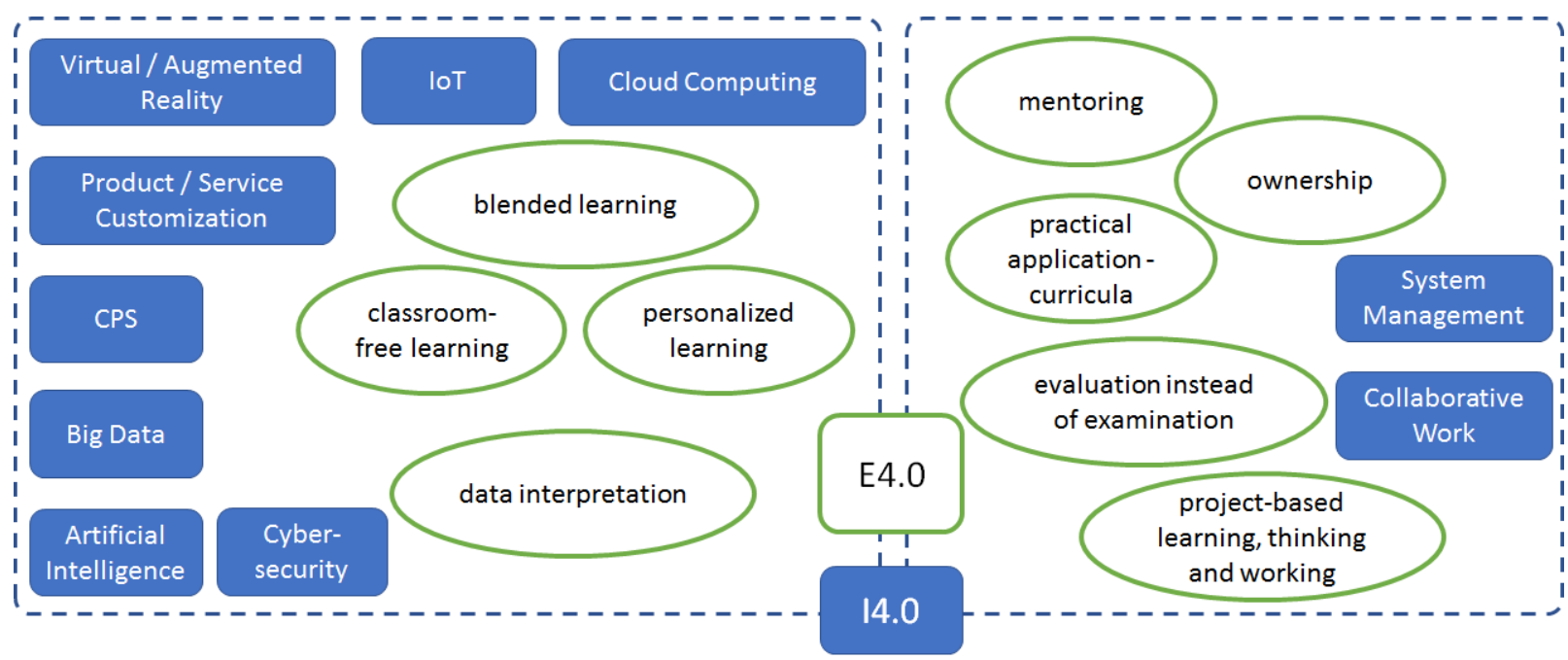

(Source: own work extended and integrated from Mogos et al. (2018) and Das et al. (2020)). 
INTERNATIONAL JOURNAL OF ENTREPRENEURIAL KNOWLEDGE

Issue 2, volume 8, ISSN 2336-2960 (Online)

www.ijek.org

Cloud computing, IoT, virtual/augmented reality and CPS are needed to facilitate classroom-free, blended and personalized learning (e.g., learning at different places at different times, flexibility to modify the learning process and tools with different interconnected devices and specific preferences, simulate real-world problems). Then, Big Data and artificial intelligence are important to develop complex decision making models with extended multi-source data. In this context, cyber-security protocols are needed to keep security through the networked devices and information flow. Finally, collaborative work and system management skills are required for the appropriate management of the interconnected learning process with remote mentoring and continuous evaluation of the virtual teaching / learning processes.

Particularly for entrepreneurship, social support and engineering education, initial efforts must be focused on the most appropriate management of the available technological tools. Figure 2 presents the person-focused baseline I4.0 conceptual model to address these needs. In the following sections, the adaptation of this model is described for each objective.

\section{Figure 2 General person-focused management of I4.0 tools for entrepreneurship and E4.0}

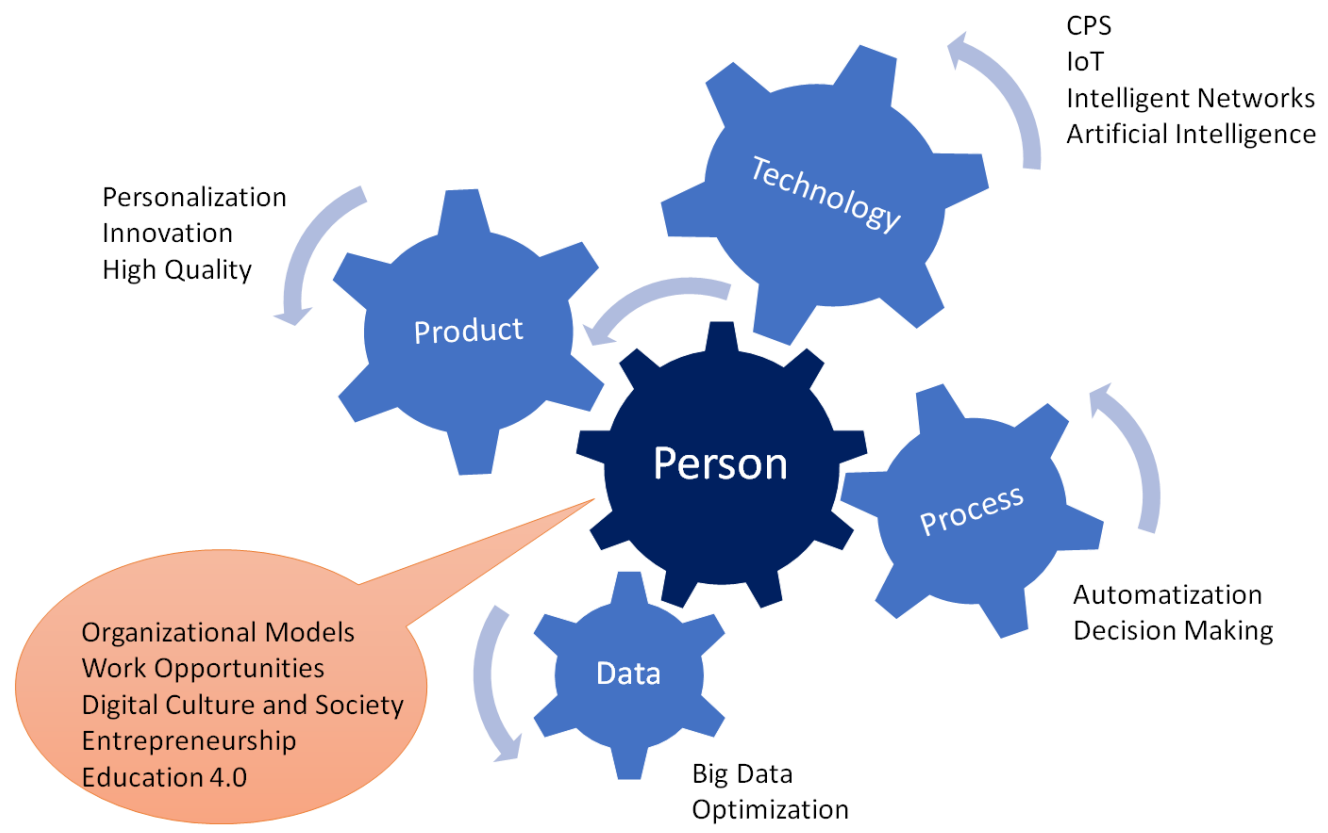

(Source: own work).

\section{PERSON-FOCUSED APPROACH FOR ENTREPRENEURSHIP}

Mentoring between academy / industry and students / entrepreneurs must be facilitated through I4.0 tools. For entrepreneurship, which is defined as the creation or extraction of "value", there must be the means to develop, organize or manage new business ventures considering its risks and ability to make profits (Gaddefors \& Anderson, 2017). Among the risks which affect entrepreneurship, the following can be mentioned: lack of funding, poor business decisions, lack of supporting government policies, economic crisis, and small or inexistent market demand.

As funding and decision making are important aspects for any business, E4.0/I4.0 must be aimed to reduce their associated risks. In (Wynand \& Sinha, 2018) the use of information and communication technology (ICT) to facilitate electronic learning (e-learning) was identified as important for I4.0 and a 
INTERNATIONAL JOURNAL OF ENTREPRENEURIAL KNOWLEDGE

Issue 2, volume 8, ISSN 2336-2960 (Online)

www.ijek.org

required asset for E4.0. Thus, proficiency in this area is needed to reduce the risks of the entrepreneurship efforts. However, as discussed in (Wynand \& Sinha, 2018), this is restricted in emerging economies.

Figure 3 presents the conceptual model to integrate the limited ICT into the innovation process of entrepreneurs. Note that the identification of opportunities for new markets through tools of strategic planning (i.e., Blue Ocean) can be performed more quickly by the standard use of the Internet. Then, a consultancy service (provided by a network of academics and industry professionals) can support the entrepreneur with the following aspects:

- Clear identification of the new market (product and/or service).

- Demand forecasting within the short and medium terms.

- Assessment of the required infrastructure and operational costs.

- In case of a manufacturing process for a new product: identification of raw materials and the most appropriate providers, value-adding processes, visualization of production line through simulation / virtual system, cycle time estimation, optimization of resources, distribution planning.

- In case of a service: value-adding strategy, image design, design of service line, Customer Relationships Management (CRM), facility layout.

- Design of specialized training through remote teaching, Massive Open Online Courses (MOOC) and simulated systems.

\section{Figure 3 Person-focused management of I4.0/E4.0 tools for entrepreneurship}

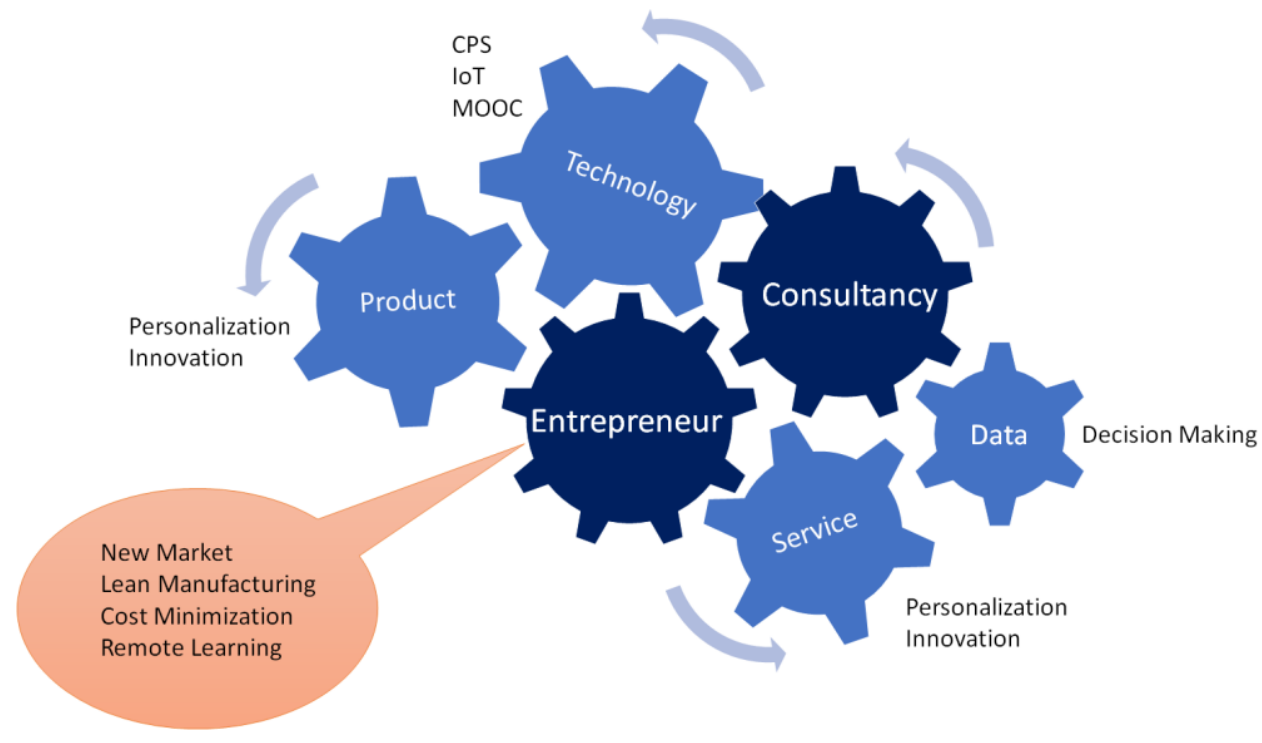

(Source: own work).

Note that the consultancy service must be performed through an internet-based platform with cybersecurity protocols. For real-time evaluation of the implementation (i.e., live feedback process) the interconnection of devices from both, users-entrepreneurs and providers-consultants, must be realized. Due to limited economic restrictions, platforms such as WhatsApp and Telegram can facilitate this interaction. Also, the support of software engineering students at BSc/MSc levels can support the development of Android/OS platforms which can address the management process required for each service/product line and send this information to the consultancy group for assessment. In this context, many programming platforms are open source with free commercial license. 
INTERNATIONAL JOURNAL OF ENTREPRENEURIAL KNOWLEDGE

Issue 2, volume 8, ISSN 2336-2960 (Online)

www.ijek.org

Specialized training can be performed also through the development of MOOC and virtual/augmented reality systems (i.e., CPS) which can support remote teaching / learning. Examples of such virtual systems were presented in (Mourtzis et al., 2018; Salah et al., 2019).

As more intuitive media software becomes available at low costs, platforms such as Doodly can help the consultants and entrepreneurs to produce media videos without extensive technical knowledge within a short period of time. This media then can be used for marketing, product / service introduction, and teaching.

\section{PERSON-FOCUSED APPROACH FOR SOCIAL ADVANCES}

Every industrial revolution brought with it benefits and challenges to the socioeconomic status of the countries that have engaged in such transformation. All these industrial revolutions have resulted in economic growth, increased productivity, and advanced welfare in the countries that managed to reap most of its positive impact, including from high-quality goods and services (Morrar et al., 2017). Social challenges are mainly at immense risk of cybercrime due to increased connectivity, and job losses due to the automation of large segments of operations in many industries as part of I4.0 (Morrar et al., 2017). The traditional industrial leaders could quickly find themselves in the role of mere suppliers, who are completely interchangeable, if they are unable to provide consumers with custom-fit "smart services". Open innovation processes, integration of (end) customers in the design and production process along with targeted big data analytics enable a variety of new business models and thus put the time-tested ones under considerable pressure.

Following the concept of I4.0, it is apparent that the process of digitization will transform many things. It is striking, however, that large sectors of society have yet to deal with this issue very intensively (Buhr, 2015). Thus, it is important to take into account that I4.0 is not only about technology, but about its impact on various sectors of the human society and its implications. Figure 4 shows some considerations of I4.0 for the development of human society.

\section{Figure 4 Impact areas of industry 4.0 in social development}

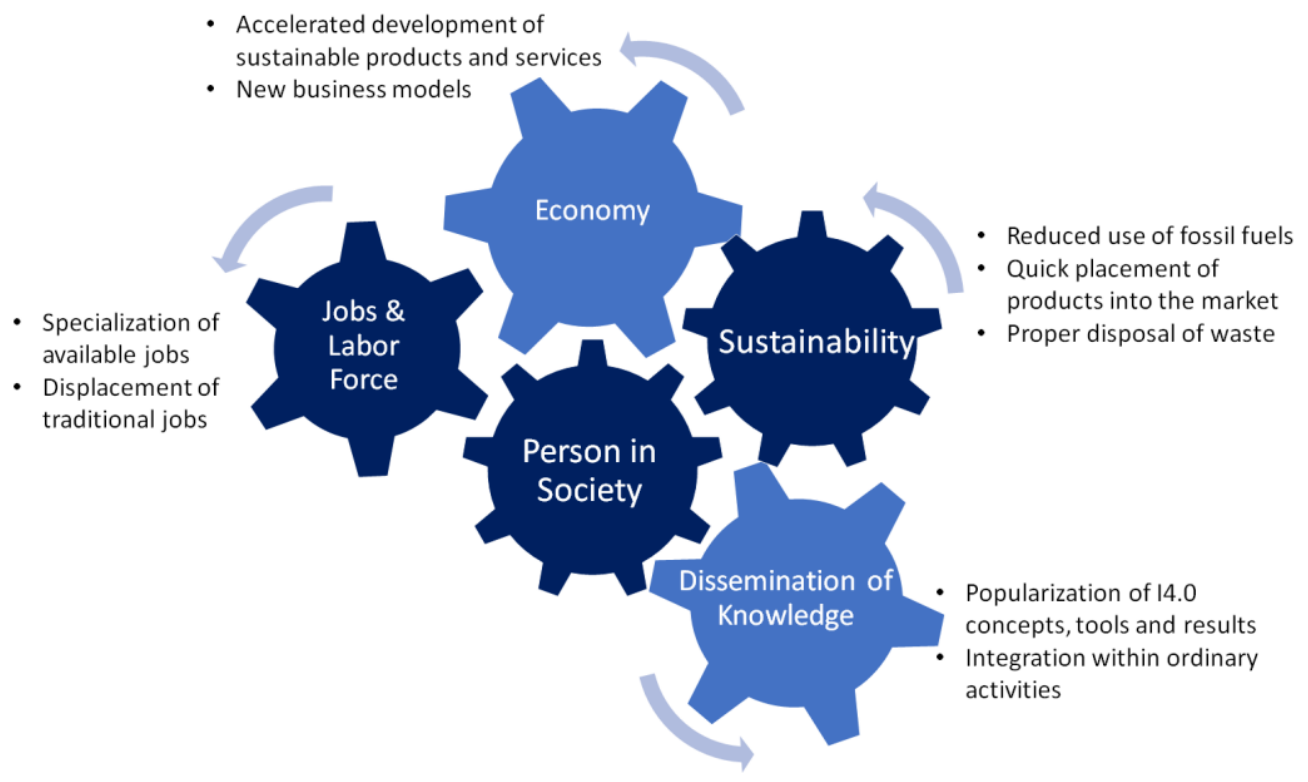

(Source: own work). 


\section{INTERNATIONAL JOURNAL OF ENTREPRENEURIAL KNOWLEDGE}

Issue 2, volume 8, ISSN 2336-2960 (Online)

www.ijek.org

Nowadays, society shows diverse trends on the ecological aspects of production and the need for goods and services: on one hand there are requirements for the increasingly fast acquisition of products and, on the other hand, ecological transportation of these products which strongly pose the need to increase sustainable technologies and renewable energy for the benefit of the environment. Nowadays, I4.0 is also coping with the necessity of producing with compliance of environmental restrictions in order to be geared towards sustainability. The main environmental pressure on digital technologies are related to the increasing trend in energy demand, and the urgent requirement of adopting low-carbon energy systems. It is clear that the I4.0 guiding principle must be focused also on providing solutions to the ecological problems faced by production as a consequence of boosting productivity, revenue growth, and competitiveness (Bonilla et al., 2018).

As part of the technological needs that are necessary in the areas of I4.0, another important phenomenon is the derivations of the effects on the labor or workforce at various levels. It is likely that at the micro company or work level, some jobs will disappear as computerization and new machines take on more face-to-face tasks from human workers. At the same time, new technologies can give rise to new types of jobs because of the new opportunities offered by these technologies. These new types of jobs are often jobs that emerge thanks to the digitization and expansion of the Internet (Krull, 2016).

As part of the economy and related to the workforce, new business models emerge based on digital technologies and job diversification. I4.0 may also lead to significant changes in existing business models, allowing new ways to create value. These changes are expected to result in the transformation of traditional value chains and create entirely new business models that enable higher levels of consumer involvement (Horváth et al., 2019).

At the same time, in all these areas described, an important part is the popularization in society of the technologies described, as well as their incorporation into daily or ordinary activities. As an active part of industrial transformation policies, the incorporation of technological elements in people's daily lives is also an essential part. I4.0 is not only about technological elements, but about their application to essential human needs.

These aspects complement the entrepreneurial faculties of I4.0. Currently, investment on human intellect and Artificial Intelligence are required to establish the basis for I4.0 implementation. Because business vocation focuses on creating novel economic opportunities, the development of cloud services and remote manufacturing systems are being improved by these investments, allowing the reduction of market research and production costs (Bakator et al., 2018). This is also aimed to overcome the social fear regarding full automatization and its implication to some jobs. By doing this investment, it is expected that I4.0 technologies and paradigms can be fully accepted for social entrepreneurship by 2030 (Popkova and Sergi, 2020).

\section{PERSON-FOCUSED APPROACH FOR ENGINEERING EDUCATION}

Organizations dependent on higher educational activity and development are more open to strategies in order to establish cooperation with other companies as well as with other universities. The transformation of traditional production systems into smart factories, and the increased need for higher technological expertise from employees, requires the ability to deal with complexity, problem solving and overlapping process thinking and flexibility (Stachová et al., 2019).

I4.0 has an original conception based on the generation of sustained high-tech strategies in manufacturing, communication and information technologies that allow the optimization of processes (Coskun et al., 2019). Consequently, engineering is an essential resource for the development of strategies 


\section{INTERNATIONAL JOURNAL OF ENTREPRENEURIAL KNOWLEDGE}

Issue 2, volume 8, ISSN 2336-2960 (Online)

www.ijek.org

and processes for I4.0 as it is focused on: (1) the development and application of emerging technologies, as well as their incorporation into current systems, and (2) the person-focused education approach in terms of the skilled workforce and its educational training process required for the insertion of students within the I4.0 labor market.

Because current technological changes occur fast, leading to a rapid obsolescence of knowledge, expertise, devices and equipment (Das et al., 2020), strategies are required to constantly update these resources. Because the constant technological modernization is unsustainable for the industry, the acquisition and application of engineering knowledge and the development of skills required by I4.0 may become an area of opportunity for universities.

However, current engineering education seeks specialization and convergence in certain areas of knowledge, generally basic science and practical skills. In this sense, although college education models contemplate common resources for the formation of basic knowledge, these are independent of other engineering fields. As a result, the integration of new education requirements in engineering curricula tends to be limited by the isolation of the available resources.

Since the acquisition of new knowledge is generally shifted to research areas, the alignment of I4.0/E4.0 knowledge can lead to an imbalance in favor of higher education to the detriment of the contribution of technical education without the appropriate curricular strategies (Tenberg et al., 2017). In addition, current education is based on the "empty container paradigm" where students enrolled in a course have no prior knowledge of the topic. Also, the linear learning process affects the assimilation of knowledge due to the significant gap between the acquisition of theoretical knowledge and its practical application. In this regard, Das et al. (2020) identify two challenges that must be addressed in order to transit to a desirable engineering college education ecosystem aligned to I4.0:

- Traditional semester-based courses do not allow effective integration of specific I4.0 content. In this case, new approaches on personalized, flexible and multidisciplinary curricular plans based on the skills and the development in I4.0 of the future worker should be a reliable alternative.

- In general, the university system underestimates workforce preparation. Here, college education to prepare students apt for research and skilled to develop tasks of I4.0 should be considered in the curricula design.

The characteristics of education in I4.0, previously defined as E4.0, includes the diversification of time and place, personalized learning, free choice, project-based learning, field experience, data interpretation, students' ownership, and mentoring increase (Fisk, 2017). According to Onar et al. (2018) the engineering E4.0 requires education content in data and computing technologies, value-added automated operation, virtual labs and augmented reality for education, gamification oriented and analytic learning. In this regard, Das et al. (2020) categorize the engineering competencies in: data science and advanced analysis (Big Data), novel human-machine interfaces, digital-to-physical transfer technologies (e.g., 3D printing), advanced simulation and virtual plant modeling, data communication and networks, system automation, artificial intelligence, robotics, programming skills, close-loop integrated product, control and management of process quality systems, real-time inventory, and logistics optimization systems.

As it can be noticed, each engineering competence constitutes an extended specialization field whose expertise cannot be approached through usual college education. Therefore, according to Ekren et al. (2020) educational methods in engineering should train the students to acquire and use knowledge through the available sea of data. In addition, students should base their learning in critical, holistic and interdisciplinary thinking, problem solving, creativity and innovation, communication and collaboration (Neaga, 2019; Ekren et al., 2020). 


\section{INTERNATIONAL JOURNAL OF ENTREPRENEURIAL KNOWLEDGE}

Issue 2, volume 8, ISSN 2336-2960 (Online)

www.ijek.org

In this regard, shifting from the traditional teaching courses to the framework of E4.0 requires a careful design and combination of the traditional manufacturing techniques with the technologies introduced by I4.0 (Mourtzis et al., 2018). E4.0 considers on one hand, the exploitation of the developed technologies (e.g. advanced visualization techniques that integrate virtual reality) to facilitate the teaching process and, on the other hand, the methods and workshops that will familiarize the aspiring engineers with these technologies, as they will work in I4.0 environments (Mourtzis et al., 2018). Figure 5 shows the personbased approach for engineering projects with various tools from I4.0. This conceptual model offers a global perspective of engineering E4.0. For this, it is necessary to define laboratory activities with the technologies described, as well as collaborative work strategies for the development of activities in the project.

\section{Figure 5 Simplified model for development of engineering projects with $\mathbf{I} 4.0$ applications}

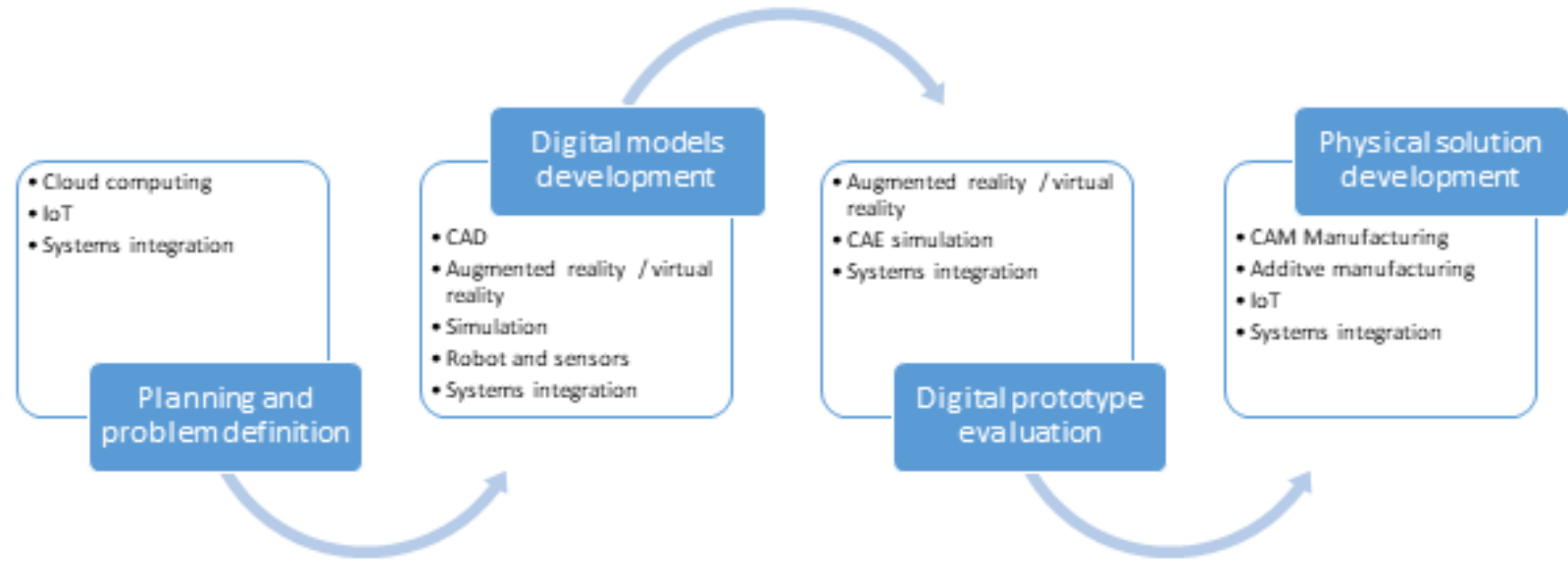

(Source: own work).

First, planning and scheduling of the tasks to be carried out by the students is defined. At this point, the connectivity and collaboration must be performed through socio-technical working systems via clouds, ubiquitous computing, product-lifecycle management and product data management. Thus, human work processes are increasingly being transferred to virtual spaces of an internationally networked world (Schuster et al, 2015). Additionally, definition of the problem that the student wants to solve is necessary. Here, information from the Internet is important to find the data and numbers necessary to obtain a global framework of the problem.

Second, the development of digital CAD models allows the student to propose multiple solutions and proposals within various areas of engineering, linked to the use of robots, sensors, devices, people and systems. Smart factories are also related to some interesting software methodologies such as virtual reality, augmented reality, simulations and virtual prototyping. These technologies enable students to see and learn about the future of the products in the simulated world before they are actually produced and presented to the market (Oztemel et al., 2020).

Third, the application of technologies for evaluating digital models is introduced, where the application of CAE technologies, virtual and augmented reality allow the students to generate analysis of the structure, space and functions of their solutions, together with the use of smart devices, which broadens their experience of collaboration with other project members. Simulations leverage real-time data to mirror the physical world in a virtual model, which can include machines, products, and humans. This also allows students to test and optimize the machine settings for the next product in line in the virtual 
INTERNATIONAL JOURNAL OF ENTREPRENEURIAL KNOWLEDGE

Issue 2, volume 8, ISSN 2336-2960 (Online)

www.ijek.org

world before the physical changeover, thereby driving down machine setup times and increasing quality (Bahrin et al, 2016).

Fourth, the development of a manufacturing model is important for the evaluation of the proposed solution. As this requires implementation, the models and their associated information / data must be uploaded to the cloud. Particularly, additive manufacturing models which are used to produce small batches of customized products will reduce transport distances and stock on-hand on I4.0 systems (Bahrin et al., 2016).

\section{CONCLUSIONS AND FUTURE WORK}

While integration of technology is the main feature of I4.0, the person-based implementation must be considered to ensure proper social acceptance, enhancement of job creation in the presence of inevitable automatization, lean production of new and customized products, and comprehensive learning skills as established by the E4.0 paradigm.

In this regard, the present work analyzed the main features of I4.0 to propose a set of conceptual models to address three main aspects in emerging economies: entrepreneurship, social welfare, and engineering education. As discussed, I4.0 can have a positive impact on entrepreneurship by providing the means for collaboration with mentors, virtual consultancy, simulation of planned processes and reduction of decision times.

On the other hand, social advances related to environmental care, job creation, dissemination of knowledge, and sustainable product development, can be achieved through I4.0. In this context, E4.0 will be a great facilitator to provide the labor force with the necessary skills for I4.0. Note that, as I4.0 requires novel technology applications, engineering education must evolve to E4.0 faster than other disciplines.

Interconnectivity of smart devices is a main feature required to establish the basic steps of I4.0/E4.0. The situation of the COVID-19 pandemic has accelerated the efforts to accomplish this task in all economies around the world and Latin America is no exception. From delivery of food services to online courses, interconnectivity has been enhanced for different contexts of our daily lives.

Hence, entrepreneurship, social welfare and engineering education can be more achievable during the post-COVID-19 era and people must be aware of this.

As future work the following aspects are considered:

- Perform a selection of specific technological and managerial tools for I4.0 on business ventures (small and medium enterprises). A case study is on development.

- Document the teaching/learning experience of remote education during the COVID-19 pandemic to establish a protocol for E4.0 (particularly for laboratory work in engineering studies).

- Collaborative simulation of manufacturing processes using free-license applications on mobile devices.

\section{REFERENCES}




\section{INTERNATIONAL JOURNAL OF ENTREPRENEURIAL KNOWLEDGE}

Issue 2, volume 8, ISSN 2336-2960 (Online)

www.ijek.org

Antonelli, D., D'Addona, D., Maffei, A., Modrak, V., Putnik, G., Stadnicka, D., \& Stylios, C. (2019). Tiphys: An Open Networked Platform for Higher Education on Industry 4.0. Procedia CIRP, 79, 706 - 711. https://doi.org/10.1016/j.procir.2019.02.128

Bahrin, M. A. K., Othman, M. F., Azli, N. H. N., \& Talib, M. F. (2016). Industry 4.0: A review on industrial automation and robotic. Jurnal Teknologi, 78, 6-13. https://doi.org/10.11113/jt.v78.9285

Bakator, M., Đorđević, D., Ćoćkalo, D., Nikolić, M., \& Vorkapić, M. [2018]. Lean startups with industry 4.0 technologies: Overcoming the challenges of youth entrepreneurship in Serbia. Journal of Engineering Management and Competitiveness (JEMC), 8(2), 89-101. Retrieved from https:/ / scindeks.ceon.rs/Article.aspx?artid=2334-96381802089B

Benesova, A., \& Tupa, J, (2017). Requirements for Education and Qualification of People in Industry 4.0. Procedia Manufacturing, 11, 2195 - 2202. https://doi.org/10.1016/j.promfg.2017.07.366

Bogoviz, A. (2019). Industry 4.0 as a New Vector of Growth and Development of Knowledge Economy. In: Industry 4.0: Industrial Revolution of the 21st Century, Studies in Systems, Decision and Control, E. G. Popkova et al. (eds.), Springer International Publishing, 85-91. https://doi.org/10.1007/978-3030-39319-9_9

Bonilla, S. H., Silva, H. R., Terra da Silva, M., Franco Gonçalves, R., \& Sacomano, J. B. (2018). Industry 4.0 and sustainability implications: A scenario-based analysis of the impacts and challenges. Sustainability, 10(10), 3740. https://doi.org/10.3390/su10103740

Buhr, D. (2015). Social innovation policy for Industry 4.0. Friedrich-Ebert-Stiftung, Division for Social and Economic Policies, University of Tuebingen: Germany. Retrieved from https://library.fes.de/pdffiles/wiso/11479.pdf

Cantú-Cavada, M., Bobek, V., \& Maček, A. (2017). Motivation Factors for Female Entrepreneurship in Mexico. Entrepreneurial Business and Economics Review, 5(3), 133-148. https://doi.org/10.15678/EBER.2017.050307

Cevik-Onar, S., Ustundag, A., Kadaifci, C.., Oztaysi, B. (2018). The Changing Role of Engineering Education in Industry 4.0 Era. In: Industry 4.0: Managing the Digital Transformation. Springer Series in Advanced Manufacturing. Springer, Cham., 137-151. https://doi.org/10.1007/978-3-319-578705_8

Coşkun, S., Kayıkc1, Y., Gençay, E. (2019). Adapting Engineering Education to Industry 4.0 Vision. Technologies, 7(1), 10. https://doi.org/10.3390/technologies7010010

Das, S., Kleinke, E., \& Pistrui, D. (2020). Reimagining Engineering Education: Does Industry 4.0 Need Education 4.0? In Proc. of the 2020 ASEE Virtual Annual Conference Content Access, American Society for Engineering Education (ed.), 1 - 20. https://doi.org/10.18260/1-2--35136

Ekren, B.Y. and Kumar, V. (2020). Engineering education towards industry 4.0. In Proc. of the 10th Annual International Conference on Industrial Engineering and Operations Management (IEOM), 2886-2893. Retrieved from https://uwe-repository.worktribe.com/output/5129502

Fisk, P. (2017). Education 4.0 ... the future of learning will be dramatically different, in school and throughout life. Gamechangers. Retrieved from https://www.thegeniusworks.com/2017/01/futureeducation-young-everyone-taught-together/

Gaddefors, J., \& Anderson, A. (2017). Entrepreneursheep and context: when entrepreneurship is greater than entrepreneurs. International Journal of Entrepreneurial Behavior \& Research, 23(2), 267-278. https://doi.org/10.1108/IJEBR-01-2016-0040

Hecklau, F., Galeitzke, M., Flachs, S., \& Kohl, H. (2016). Holistic Approach for Human Resource Management in Industry 4.0. Procedia CIRP, 54, 1 - 6. https://doi.org/10.1016/j.procir.2016.05.102

Horváth, D., \& Szabó, R. Z. (2019). Driving forces and barriers of Industry 4.0: Do multinational and small and medium-sized companies have equal opportunities? Technological Forecasting and Social Change, 146, 119-132. https://doi.org/10.1016/j.techfore.2019.05.021

Krull, S. (2016). El cambio tecnológico y el nuevo contexto del empleo tendencias generales y en América Latina (The Technological Change and the New Context for Employment: General Tendencies in Latin America). Comisión Económica para América Latina y el Caribe (CEPAL), United Nations. Retrieved from https://repositorio.cepal.org/handle/11362/40856 
INTERNATIONAL JOURNAL OF ENTREPRENEURIAL KNOWLEDGE

Issue 2, volume 8, ISSN 2336-2960 (Online)

www.ijek.org

Mogos, R.I., Bodea, C.N., Dascalu, M.I., Safonkina, O., Lazarou, E., Trifan, E.L., \& Nemoianu, I.V. (2018). Technology Enhanced Learning for Industry 4.0 Engineering Education. Rev. Roum. Sci. Techn., 63(4), 429 - 435. Retrieved from https://www.researchgate.net/publication/330638538

Morrar, R., Arman, H., \& Mousa, S. (2017). The fourth industrial revolution (Industry 4.0): A social innovation perspective. Technology Innovation Management Review, 7(11), 12-20. http://doi.org/10.22215/timreview/1117

Motyl, B., Baronio, G., Uberti, S., Speranza, D., \& Filippi, S. (2017). How will change the future engineers' skills in the Industry 4.0 framework? A questionnaire survey. Procedia Manufacturing, 11, 1501 - 1509. https:// doi.org/10.1016/j.promfg.2017.07.282

Mourtzis, D., Vlachou, E., Dimitrakopoulos, G., \& Zogopoulos, V. (2018). Cyber-Physical Systems and Education 4.0 - The Teaching Factory 4.0 Concept. Procedia Manufacturing, 23, 129 - 134. https://doi.org/10.1016/j.promfg.2018.04.005

Neaga, I. (2019). Applying Industry 4.0 and Education 4.0 to Engineering Education. In Proc. of the Canadian Engineering Education Association (CEEA), paper 001, 1-6. https://doi.org/10.24908/pceea.vi0.13859

Oztemel, E., \& Gursev, S. (2020). Literature review of Industry 4.0 and related technologies. Journal of Intelligent Manufacturing, 31(1), 127-182. https://doi.org/10.1007/s10845-018-1433-8

Popkova, E.G. and Sergi, B.S. (2020). Human capital and AI in industry 4.0. Convergence and divergence in social entrepreneurship in Russia. Journal of Intellectual Capital, 21(4), 565-581. https://doi.org/10.1108/JIC-09-2019-0224

Salah, B., Abidi, M., Mian, S., Krid, M., Alkhalefah, H., \& Abdo, A. (2019). Virtual Reality-Based Engineering Education to Enhance Manufacturing Sustainability in Industry 4.0. Sustainability, 11(1477), 1-19. https://doi.org/10.3390/su11051477

Schuster, K., Groß, K., Vossen, R., Richert, A., \& Jeschke, S. (2016). Preparing for Industry 4.0Collaborative Virtual Learning Environments in Engineering Education. In: Automation, Communication and Cybernetics in Science and Engineering 2015/2016, Jeschke et al. (ed.), Springer Verlag, 417- 427. https://doi.org/10.1007/978-3-319-42620-4_33

Stachová, K., Papula, J., Stacho, Z., \& Kohnová, L. (2019). External Partnerships in Employee Education and Development as the Key to Facing Industry 4.0 Challenges. Sustainability, 11(2), 345. https://doi.org/10.3390/su11020345

Tenberg, R. \& Pittich, D. (2017). Ausbildung 4.0 oder nur 1.2? Analyse eines technisch-betrieblichen Wandels und dessen Implikationen für die technische Berufsausbildung (Training 4.0 or just 1.2? Analysis of a Technical Operational Change and its Implications for the Technical Vocational Training). Journal of Technical Education, 5(1), 27-45. Retrieved from https://www.journal-oftechnical-education.de/index.php/joted/article/view/94

Wynand, J., \& Sinha, S. (2018). Scaling Education in Emerging Markets to Participate in Industry 4.0. In Proc. of the 2018 International Conference on Intelligent and Innovative Computing Applications (ICONIC), IEEE, 1 - 6. https://doi.org/10.1109/ICONIC.2018.8601216

\section{BRIEF DESCRIPTION OF AUTHOR/AUTHORS:}

\section{Santiago-Omar Caballero-Morales, BSc., M.Sc., M., Ph.D.}

Postgraduate Department of Logistics and Supply Chain Management, Faculty of Industrial Engineering, Universidad Popular Autonoma del Estado de Puebla, 17 Sur 901, Mexico, https://upaep.mx//, santiagoomar.caballero@upaep.mx. Full-time Professor Researcher in combinatorial optimization, design of distribution networks, artificial intelligence, pattern recognition, simulation of industrial processes, supply chain planning, and service robotics.

José de Jesús Cordero Guridi, BSc., M.Sc. 
INTERNATIONAL JOURNAL OF ENTREPRENEURIAL KNOWLEDGE

Issue 2, volume 8, ISSN 2336-2960 (Online)

www.ijek.org

Faculty of Industrial Engineering, Universidad Popular Autonoma del Estado de Puebla, 17 Sur 901, Mexico, https://upaep.mx//, josejesus.cordero@upaep.mx. Full-time Professor on Industrial Engineering and Automotive Design. Researcher in Augmented and Virtual Reality, Automotive Systems Design and CAD/CAE simulations.

\section{Ricardo-Iván Alvarez-Tamayo, B.Eng., M.Sc., D.Sc.}

Postgraduate Department of Mechatronic Engineering, Faculty of Mechatronics, Electronics, Bionics, and Aerospacial, Universidad Popular Autonoma del Estado de Puebla, 17 Sur 901, Mexico, https://upaep.mx//, ricardoivan.alvarez01@upaep.mx. Full-time Professor Researcher in optical sensing, fiber optics, fiber lasers, optical properties of metamaterials, interferometry, and optomechatronics.

Luis Cuautle-Gutiérrez, B.Eng., M.Sc., D.Sc.

Faculty of Industrial Engineering, Universidad Popular Autonoma del Estado de Puebla, 17 Sur 901, Mexico, https://upaep.mx//, luis.cuautle@,upaep.mx. Department Head, Researcher in quality systems, ergonomics, augmented and virtual reality. 